\title{
Hypercalcemia of Malignancy
}

National Cancer Institute

\section{Source}

National Cancer Institute. Hypercalcemia of Malignancy. NCI Thesaurus. Code C3496.

Hypercalcemia generally develops as a late complication of malignancy; its appearance has grave prognostic significance. It remains unclear, however, whether death is associated with hypercalcemic crisis (uncontrolled or recurrent progressive hypercalcemia) or with advanced disease. Symptoms include central nervous system impairment such as delirium with prominent symptoms of personality change, cog nitive dysfunction, disorientation, incoherent speech, and psychotic symptoms such as hallucinations and delusions, smooth muscle hypotonicity, and altered cardiovascular function. 